\title{
Polystyrene/High Density Polyethylene Blends Compatibilized by a Tri-Block Copolymer I. Properties and Morphology
}

\author{
Shi-Ai Xu and Chi-Ming ChaN \\ Department of Chemical Engineering and Advanced Engineering Materials Facility, \\ The Hong Kong University of Science and Technology, \\ Clear Water Bay, Kowloon, Hong Kong
}

(Received October 16, 1997)

\begin{abstract}
The compatibilization of polystyrene (PS)/high density polyethylene (HDPE) blends was achieved by using a (styrene-ethylene/butylene-styrene) tri-block copolymer (SEBS) as a compatibilizer. The blends were prepared by a twin-screw extruder. The mechanical properties of the blends were greatly improved after addition of SEBS, suggesting the compatibilizing role of the tri-block copolymer in the immiscible PS/HDPE system. The morphology of the blends was observed by scanning electron microscopy (SEM). It was found that the copolymer is very efficient in reducing the size of the dispersed phase, and that a co-continuous two-phase structure appears as the content of SEBS increases to $4 \mathrm{wt} \%$. The results of a SEM study of the fracture surfaces of the tensile bars showed that the unmodified and modified blends exhibited different fracture characteristics. The melt rheology of the blends was investigated by capillary rheometry. The melt viscosity of the blends increases after the addition of $4 \mathrm{wt} \%$ SEBS. The thermal properties of these blends were measured by a differential scanning calorimeter (DSC). The SEBS content does not affect the glass transition temperature of the polystyrene phase and the melting point of the polyethylene phase in the blends.

KEY WORDS Polystyrene / High Density Polyethylene / Blends / Compatibilization / (StyreneEthylene/Butylene-Styrene) Tri-block Copolymer / Mechanical Properties / Morphology / Rheology / Calorimetry /
\end{abstract}

Blending different polymers into a heterophase system is a very attractive route towards new and tailor-made materials. It is also an efficient way to improve some deficient performances of many polymers. ${ }^{1}$ However, the blends of immiscible polymers prepared by a simple mixing always show very poor mechanical properties compared with the individual constituents, which results from the weak interfacial adhesion and inferior stability of the phase dispersion..$^{2-4}$ It is now recognized that compatibilization is an effective method to improve the compatibility between two immiscible polymers, resulting in great improvement in the mechanical properties. Many different compatibilization methods for polymer blends have been developed, including addition of a compatibilizer and reaction compatibilization. ${ }^{5}$

Polystyrene (PS) and polyethylene (PE) are both commercial plastics used in large quantities. PS is a typical brittle polymer with very low elongation and impact strength. While polyethylene is commercially attractive for its toughness and low-temperature impact performance. It is a very useful and profitable to toughen PS using PE. ${ }^{6-8}$ However, PS/PE blends exhibit very poor mechanical properties owing to their incompatibility. ${ }^{9-11}$ Therefore, compatibilization of PS and PE blends has been the subject of much study in recent decades. ${ }^{1,7,12-16}$

It is well known that the addition of a block or graft copolymer acting as a compatibilizer to phase-separated blends of immiscible homopolymers can result in a remarkable improvement in their mechanical properties. $^{13,17}$ Barentsen et al. ${ }^{13,15}$ and Paul et al. ${ }^{16,18}$ separately synthesized PS- $g$-PE graft copolymers by different ways, and they used these copolymers as the compatibilizers for PS/PE blends. The results show that the blends modified by the copolymers exhibit higher strength, whereas the elongation-at-break remains rather low. ${ }^{19}$ Fayt and Teyssie tried to improve the mechanical properties of PS/PE blends by using block copolymers as compatibilizers. They have extensively studied the properties and morphology of the PS/PE system in the last two decades and significantly improved the understanding of this system. ${ }^{19-22}$ However, up to now, little attention has been paid to the compatibilizing role of tri-block copolymers in the PS/PE system, especially the (styrene-ethylene/butadiene-styrene) tri-block copolymer (SEBS). The copolymer has been commercialized by Shell. Schwarz et al. $^{23,24}$ used SEBS to compatibilize immiscible blends of high density polyethylene (HDPE) and a copolymer of PS and polyether. Recently, Appleby et al. $^{25}$ investigated the impact property of PS/polypropylene (PP) and PS/low density polyethylene (LDPE) blends compatibilized by a series of hydrogenated styrene-butadiene block copolymers.

$\mathrm{Xu}$ et al. ${ }^{6-8,26}$ have successfully compatibilized blends of PS and LDPE using SEBS (G1652, Shell) as a compatibilizer. The mechanical properties, melt rheological behavior, deformation, and toughening mechanisms of PS/LDPE/SEBS blends have been extensively studied. In order to broaden the application of SEBS, its compatibilizing roles in the blends of PS/HDPE are examined in this paper. In this study, HDPE was blended with PS to improve the brittleness of PS, and SEBS (Kraton G1652, Shell) was chosen as a compatibilizer to improve the interfacial adhesion and the mechanical properties of PS/HDPE blends. The blends were prepared by a twin-screw extruder. The effects of the SEBS content on the mechanical properties, morphology, melt rheology, and thermal properties were studied extensively. 


\section{EXPERIMENTAL}

\section{Materials}

The homopolymers used were a commercial grade of PS (Styron GP66 HR3DOW, Dow Chemical Pacific Ltd.) and HDPE (Phillips 66, Marlex HMN 6060, Phillips Petroleum Company). The molecular weights of PS and HDPE were determined by gel permeation chromatography. The number-average and weight-average molecular weights of PS were determined to be 78450 and 232900 , respectively. The number-average and weightaverage molecular weights of HDPE were determined to be 14700 and 61900, respectively. SEBS (Kraton G1652) was kindly supplied by Shell with the molecular weights of the PS block and the central ethylene/butylene (EB) block being 7500 and 37500 , respectively, and the PS weight fraction being 0.286 .

\section{Blending and Sample Preparation}

The homopolymers and SEBS were dried for $24 \mathrm{~h}$ at $80^{\circ}$ and $60^{\circ} \mathrm{C}$, respectively. The blends were prepared by mixing the well-dried pellets in a conical twin-screw extruder (Haake Rheocord 9000), operating at $30 \mathrm{rpm}$. The compounds obtained were run through the extruder again to ensure homogeneous mixing. The temperatures in the three heating zones were 170,180 , and $190^{\circ} \mathrm{C}$. The temperature at the die was $200^{\circ} \mathrm{C}$. The composition of the blends was fixed at a PS/PE weight ratio of $80 / 20$, and the SEBS content varied from 0 to $10 \mathrm{wt} \%$, being defined with respect to the total weight of the blend.

The extrudates were pelletized and then dried at $80^{\circ} \mathrm{C}$ for $24 \mathrm{~h}$. Using these pellets, dumb-bell shape tensile bars (ASTM D638-91, type IV) were injection molded using a Morgan hot press. The temperatures at the barrel and Nozzle were 210 and $220^{\circ} \mathrm{C}$, respectively.

\section{Characterization of Blends}

The tensile behavior of the blends was determined with an Instron tensile tester (Model 5567) at a cross head speed of $10 \mathrm{~mm} \mathrm{~min}^{-1}$, and an extensometer with a gauge length of $25 \mathrm{~mm}$ was used to precisely measure the initial longitudinal strain in order to calculate the modulus of the specimen. At least five specimens of each composition were tested and the average values were reported. The fracture energy of the samples was obtained by integrating the area under the stress-strain curve.

The surfaces of the blend samples which fractured in liquid nitrogen and the surfaces of the tensile bars which fractured at room temperature were examined by scanning electron microscopy (JEOL, JSM-6300). The samples were coated with a thin layer of gold to minimize surface charging. The accelerating voltage and current were $15 \mathrm{kV}$ and $100 \mu \mathrm{A}$, respectively.

The melt rheological properties of the blends were measured at $200^{\circ} \mathrm{C}$ using a capillary rheometer (Rheograph 2003, Göttfert). The experiments were carried out at constant shear rates using a circular die with a $\mathrm{L} / \mathrm{D}$ ratio of $30 / 1$ (diameter $1 \mathrm{~mm}$, and length $30 \mathrm{~mm}$ ) and the shear rate varied from 40 to $1100 \mathrm{~s}^{-1}$.

Thermal analyses of the blends were performed by using a differential scanning calorimeter (Setaram DSC92). Indium, tin, lead, and zinc standards were used for temperature calibration. The specimen was initially

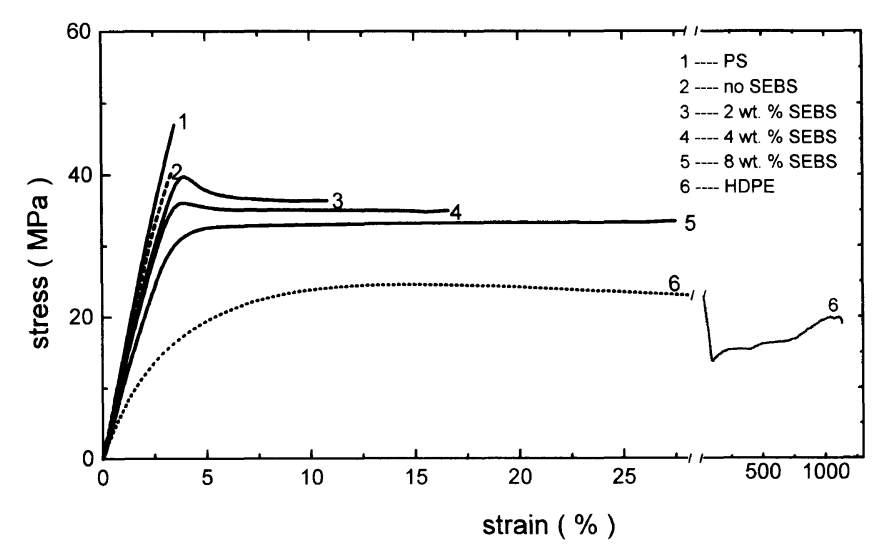

Figure 1. Stress-strain curves of PS, HDPE, and their blends (PS/HDPE 80/20).

heated to $200^{\circ} \mathrm{C}$ at a rate of $20^{\circ} \mathrm{C} \mathrm{min}^{-1}$, and held for $5 \mathrm{~min}$ at this temperature. The specimen was then cooled to $50^{\circ} \mathrm{C}$ at $10^{\circ} \mathrm{C} \mathrm{min}^{-1}$, and held at this temperature for $3 \mathrm{~min}$. These procedures were carried out to remove prior thermal histories. After these procedures, DSC scans were obtained by heating the sample to $200^{\circ} \mathrm{C}$ at a fixed heating rate of $10^{\circ} \mathrm{Cmin}^{-1}$.

\section{RESULTS AND DISCUSSION}

\section{Tensile Mechanical Properties}

Figure 1 shows the stress-strain curves of pure PS, HDPE, and the PS/HDPE (80/20) blends containing different amounts of SEBS. It can be seen that PS is a hard and brittle polymer with an ultimate elongation of less than 4\%, whereas HDPE is a typical ductile polymer with its elongation-at-break exceeding $1000 \%$. However, the blend of PS and HDPE without addition of SEBS does not display any improvement in toughness. It is still brittle and fractured in a brittle mode ( $c f$., Figure 1 curve 2 ). There is no yield point on its stress-strain curves and it broke at a strain of about $3.5 \%$. As pointed out by previous authors, ${ }^{1,13,16}$ the PS/HDPE blend combines the poorest properties of the components. However, after the addition of only $2 \mathrm{wt} \%$ of SEBS to the blend, a completely different tensile behavior occurs ( $c f$., Figure 1 curve 3 ). The blend displays a ductile behavior as indicated by the presence of a yielding point. Its stressstrain curve exhibits the characteristics of a typical toughened plastic, such as acrylonitrile-butadiene-styrene terpolymer and high impact PS. All PS/HDPE blends compatibilized by SEBS also exhibit a similar behavior. The tensile bars of these blends show whitening but no obvious necking in the tensile process.

Young's modulus of the blends as a function of SEBS content is shown in Figure 2. The moduli of pure PS and HDPE are $3200 \mathrm{MPa}$ and $1300 \mathrm{MPa}$, respectively. It can be seen from Figure 2 that the modulus of the uncompatibilized PS/HDPE blend decreases to $2700 \mathrm{MPa}$, being intermediate between PS and HDPE. The modulus of the blends decreases with increasing SEBS content. A sharp drop is observed when the content of SEBS increases from 2 to $4 \mathrm{wt} \%$. The difference between PS and these blends reflects the influence of the soft component. The blend containing $10 \mathrm{wt} \%$ of SEBS only shows a relatively small decrease (about 


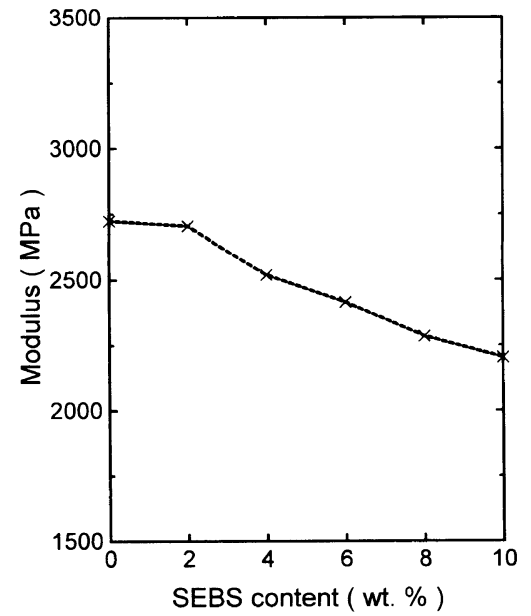

Figure 2. Plot of modulus of the blends versus SEBS content.

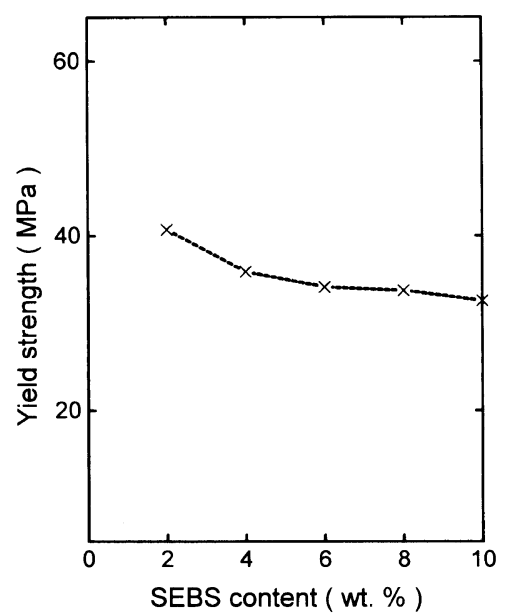

Figure 3. Plot of yield strength of the blends versus SEBS content.

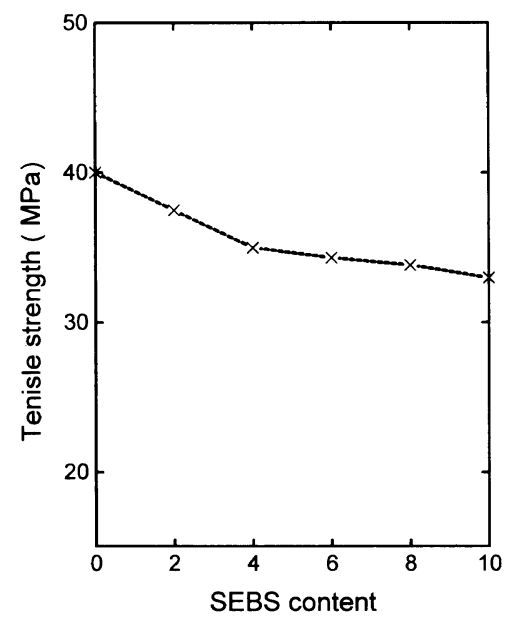

Figure 4. Plot of tensile strength of the blends versus SEBS content.

$30 \%$ ) in modulus compared to pure PS. The phenomenon that the compatibilizer produces a decrease in the modulus has been also observed in PS/LLDPE and PS/ LDPE blends. ${ }^{14,26}$ As shown in the stress-strain curves, the blend without SEBS does not show any yielding in the tensile process, whereas all the compatibilized blends exhibit a yield behavior. Generally, the yield strength of the blend compatibilized by SEBS decreases with increasing SEBS content (Figure 3), but it hardly changes when

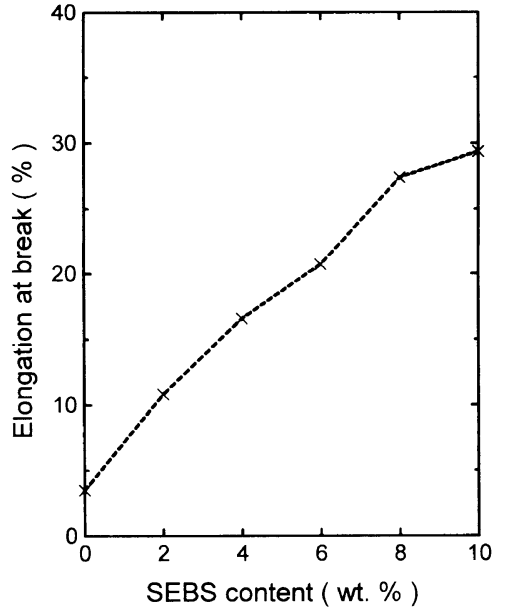

Figure 5. Plot of elongation at break of the blends versus SEBS content.

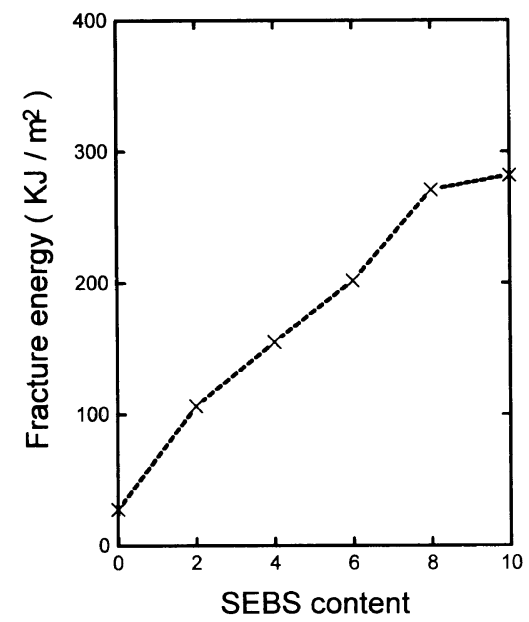

Figure 6. Plot of break energy of the blends versus SEBS content.

the content of SEBS is higher than $4 \mathrm{wt} \%$. The ultimate tensile strength of the blends as a function of SEBS content, as shown in Figure 4, exhibits a similar trend.

It is well known that when brittle PS is blended even with ductile HDPE without a compatibilizer, the toughness of the blend does not improve and the elongationat-break of the blend is very low (cf., Figure 5). These poor physical properties are attributed to the weak interfacial adhesion between the PS and PE phases owing to their immiscibility. Fayt et al. ${ }^{27}$ studied the mechanical properties of PS/HDPE blends without a compatibilizer, and found that the curves of both strength and ductility versus blend composition commonly exhibit a minimum value smaller than that of either component. However, after addition of as little as $2 \mathrm{wt} \%$ of SEBS to the blend, the elongation-at-break increases and it further increases at higher SEBS contents. These results demonstrated the effectiveness of SEBS as a compatibilizer in the PS/HDPE system. In addition, stronger interfacial adhesion results in a large increase of fracture energy which was determined by integrating the area under the stress and strain curve ( $c f$., Figure 6). The fracture energy of the blends increases with SEBS content.

From the above discussion, it can be concluded that PS is toughened by adding HDPE as a toughening modifier with SEBS as a compatibilizer. The yielding of 

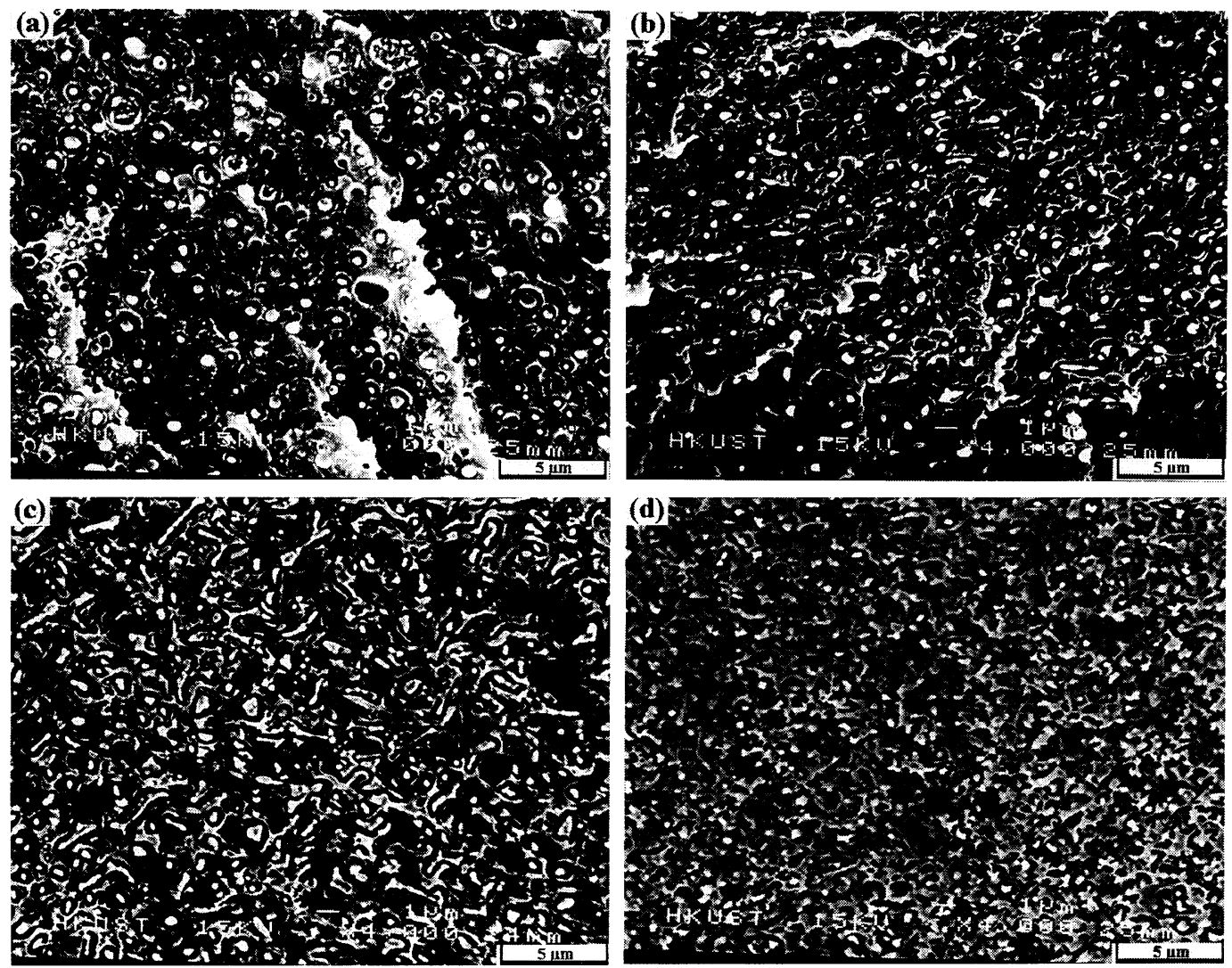

Figure 7. SEM micrographs of cryofracture surfaces in liquid nitrogen for PS/HDPE (80/20) blends containing different amounts of SEBS. (a), no SEBS; (b), $2 \mathrm{wt} \%$ SEBS; (c), $4 \mathrm{wt} \%$ SEBS; (d), $8 \mathrm{wt} \%$ SEBS.

high-impact PS occurs at a lower stress than the ultimate strength of PS, and the material undergoes a large deformation before breaking. This behavior is a result of strong adhesion between the soft phase and the hard matrix, which contributes to the control of crazing and shearing. ${ }^{28}$ The similarity in the tensile mechanical properties of high impact PS and SEBS-compatibilized PS/HDPE blends supports the anchoring efficiency of SEBS between the HDPE and PS phases. ${ }^{1}$

\section{Morphology of the Blends}

Figures 7(a)-(d) reveal SEM micrographs of the cryofracture surfaces for the blends containing different amounts of SEBS. It can be seen from Figure 7(a) that a large number of fine white particles are dispersed in the matrix of the PS/HDPE 80/20 blend without SEBS. Obviously, the white particles are the HDPE phase and the continuous matrix is the PS phase based on the composition of the blend. The size distribution of the dispersed particles is very wide, and the average diameter is about $0.4 \mu \mathrm{m}$. The two phases are well separated and many holes are present, suggesting that the dispersed particles were pulled out during the cryogenic fracture because of poor adhesion between the PS and PE phases. It is worth noting that the size of the dispersed particles in this unmodified blend is much smaller than that of many incompatible systems. ${ }^{6,9,14,18}$ The size of the dispersed particles decreases and a more homogeneous dispersion is obtained after the addition of $2 \mathrm{wt} \%$ SEBS to the blend (Figure 7(b)). A semicontinuous to continuous two-phase structure appears with increasing SEBS content to $4 \mathrm{wt} \%$ (Figure $7(\mathrm{c})$ ). The average size of the interlocked phases further decreases after the addition of $8 \mathrm{wt} \%$ SEBS (Figure 7(d)). Blends that exhibit a co-continuous morphology after the addition of a compatibilizer have been reported in other systems. ${ }^{1,23}$

Figures 8(a)-(d) show the morphology of the fracture surfaces of the tensile bars. The smooth fracture surface of the unmodified blend indicates that the fracture mode was brittle (Figure 8(a)), as evidenced by stress-strain measurements. The dispersed HDPE particles do not exhibit any deformation. On the contrary, the rough fracture surfaces of the compatibilized blends indicate that plastic deformation occurs (Figures $8(\mathrm{~b})-(\mathrm{d})$ ). This suggests that the transition from brittle to ductile (tough) failure takes place after compatibilization. The same result was also found in PS/LDPE blends modified by a bi-block copolymer ${ }^{29}$ and a tri-block copolymer. ${ }^{26}$ Such results can be explained in terms of adhesion between HDPE particles and the PS matrix. When a sample is strained, the stress applied on the dispersed particles depends mainly on their interfacial adhesion with PS. In the unmodified blend, the interfacial adhesion is very weak, and the stress cannot be transferred to the HDPE particles through the interface. The dispersed HDPE particles acting as stress concentrators cause high local stresses at the interface. As deformation proceeds, local failure occurs first along the interface, resulting in coalescence of voids, ${ }^{30}$ and fracture of the specimen is observed at very low ultimate elongations. ${ }^{31}$ When SEBS is added, the HDPE particles are strongly anchored in the PS matrix. This improvement in the interface adhesion is essential for the transfer of internal stresses through the interfaces and for preventing local failure. 

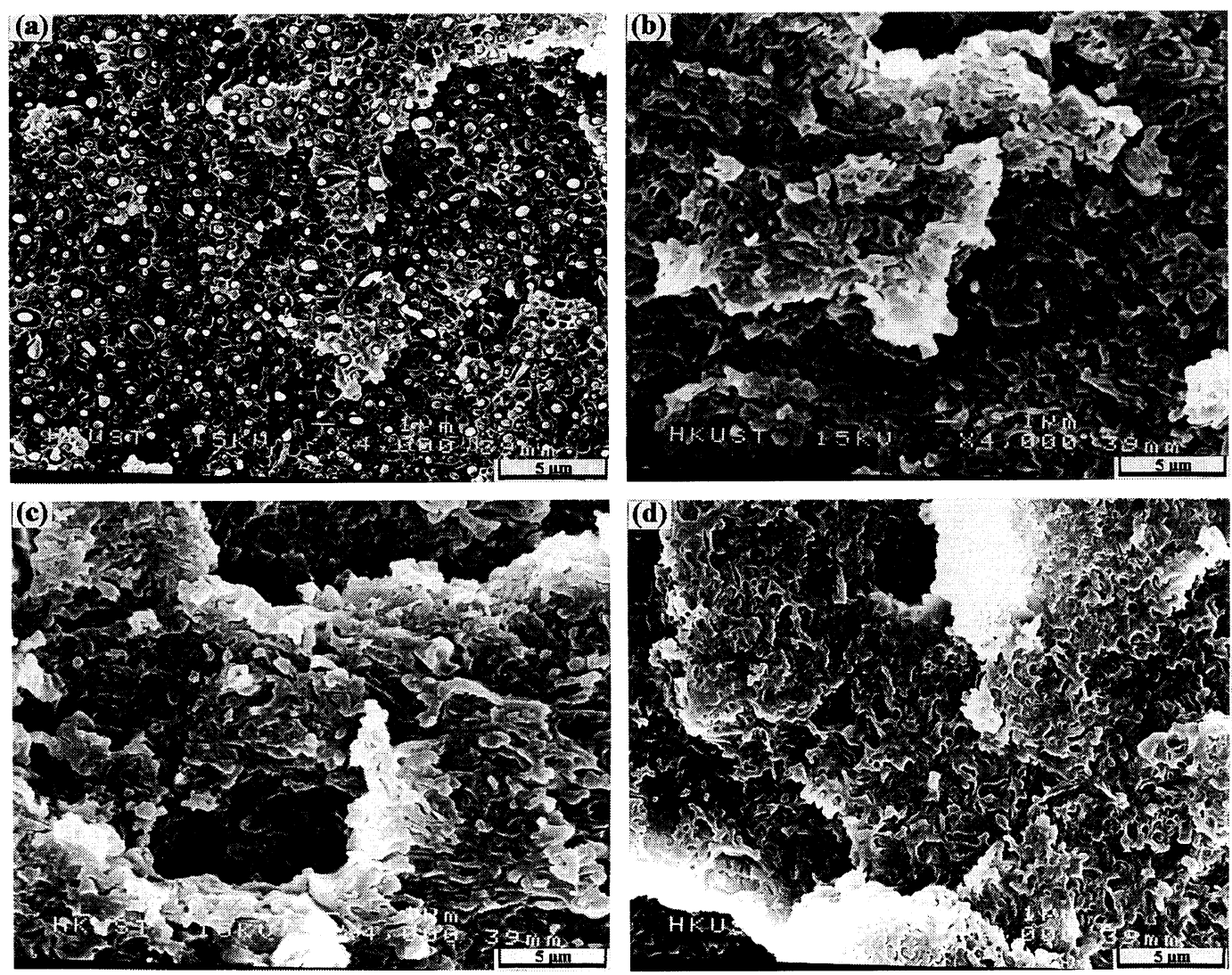

Figure 8. SEM micrographs of tensile fracture surfaces at room temperature for PS/HDPE (80/20) blends containing different amounts of SEBS. (a), no SEBS; (b), $2 \mathrm{wt} \%$ SEBS; (c), $4 \mathrm{wt} \%$ SEBS; (d), $8 \mathrm{wt} \%$ SEBS.

Accordingly, formation of voids is hindered, and yielding appears in the tensile process of the compatibilized blends. After yielding, the tensile bars exhibit colddrawing characteristics and fracture at high elongations.

\section{Melt Rheological Properties}

Figures 9(a)-(c) show the melt viscosity of the blends containing different SEBS contents at three shear rates. At the shear rates studied, the variation of viscosity with SEBS content exhibits the same trend, i.e., the melt viscosity of the blends hardly changes after addition of $2 \mathrm{wt} \%$ SEBS, whereas it increases sharply when the content of SEBS increases from 2 to $4 \mathrm{wt} \%$. Further increase in SEBS content does not cause any significant change in the viscosity.

The variation of viscosity with SEBS content reflects the changes of the interfacial state and the morphology of the blends. When only $2 \mathrm{wt} \%$ SEBS was added to the PS/HDPE 80/20 blend, the interfacial adhesion was very weak and the HDPE phase dispersed in the PS matrix in the form of spherical particles. This morphology is very similar to that of the unmodified blend; therefore, the melt viscosity of the blend does change noticeably. With the SEBS content increased from 2 to $4 \mathrm{wt} \%$, the density of the compatibilizer at the interfaces increases, resulting in stronger adhesion between the PS and PE phases. The morphology of the blend changes from a single phase continuous structure to a bi-continuous one; hence, the melt viscosity of the blend increases greatly. When the SEBS content exceeds $4 \mathrm{wt} \%$, the density of the compatibilizer at the interface reaches saturation. No noticeable changes in morphology and viscosity are

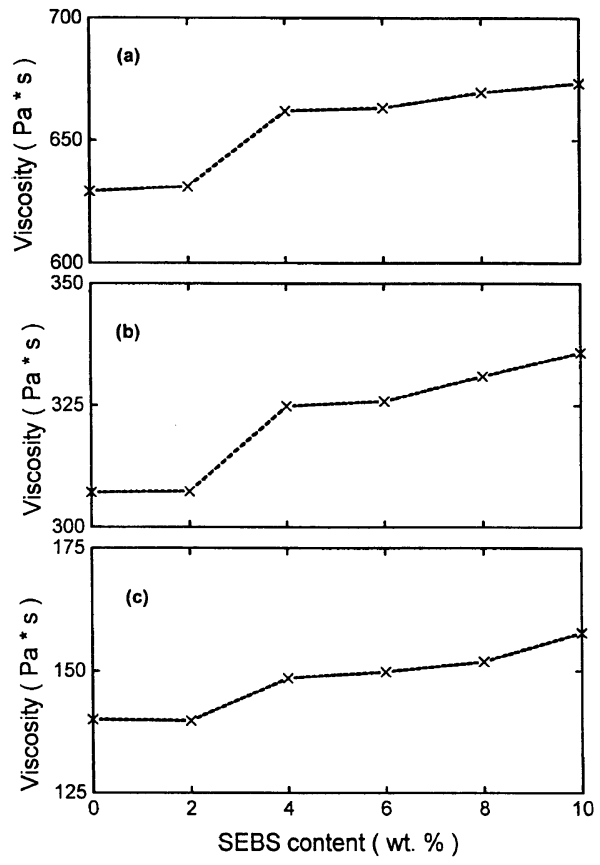

Figure 9. Plots of melt viscosity of the blends versus SEBS content: (a), $\gamma=100 \mathrm{~s}^{-1}$; (b), $\gamma=300 \mathrm{~s}^{-1}$; (c), $\gamma=1000 \mathrm{~s}^{-1}$.

observed.

\section{Thermal Analysis}

The differential scanning calorimetry (DSC) heating curves of the three components in these blends are shown in Figure 10. It can be concluded from this figure that the SEBS used in this study is noncrystalline. In addition, 


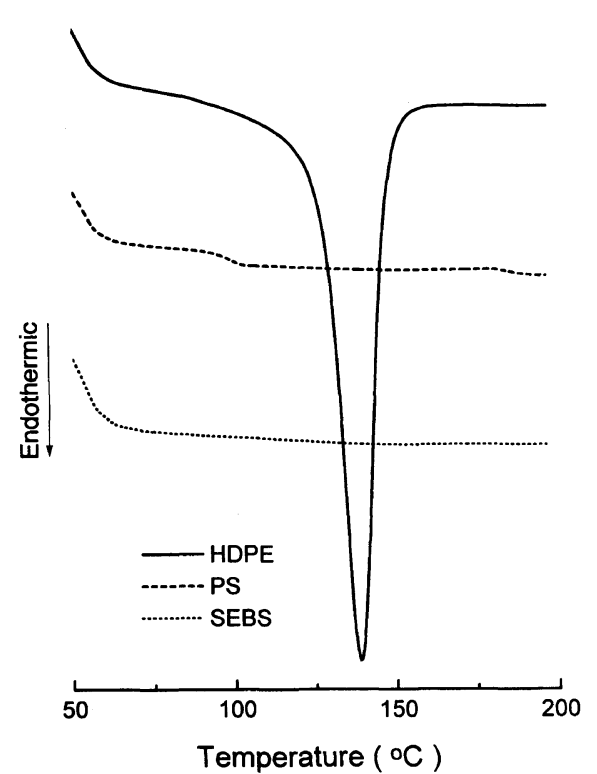

Figure 10. DSC heating curves of pure PS, HDPE, and SEBS.

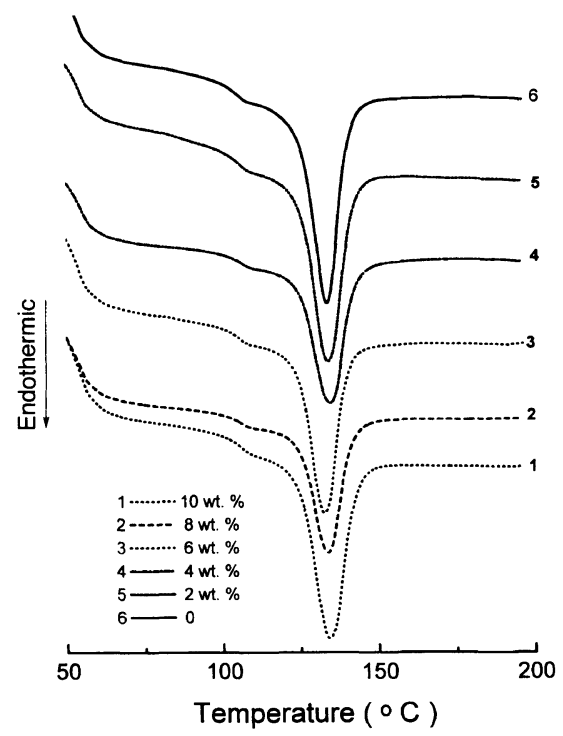

Figure 11. DSC heating curves of the PS/HDPE (80/20) blends containing different amounts of SEBS.

the glass transition temperature of the PS block is difficult to be identified from the heating curve of SEBS, possibly due to the low weight fraction of the PS block in the copolymer. The heating curve of pure HDPE reveals a large endotherm peak, and its melting point determined from the melting peak is $138.7^{\circ} \mathrm{C}$. In the DSC curve of pure polystyrene, the glass transition temperature is easily identified to be at $98.5^{\circ} \mathrm{C}$.

The heating curves of the blends containing different contents of SEBS are shown in Figure 11. In these curves, the glass transition of the PS phase and an endotherm peak of the HDPE phase are easily identified and the results are summarized in Table I. The heat of fusion can be obtained by integrating the area under the peak. The degree of crystallinity $\left(X_{\mathrm{c}}\right)$ of the HDPE phase in its pure state and in the blends is determined the following relation:

$$
X_{\mathrm{c}}=\frac{\Delta H_{\mathrm{m}}}{w(1-\phi) \Delta H_{\mathrm{m}}^{\mathrm{o}}} \times 100
$$

Table I. The glass transition temperature of the PS phase and the melting point and crystallinity of the HDPE phase in PS/HDPE (80/20) blends determined by DSC

\begin{tabular}{lrrrrrrrr}
\hline & & & \multicolumn{6}{c}{ SEBS content $/ \mathrm{wt} \%$} \\
\cline { 4 - 9 } & & HDPE & PS & \multicolumn{1}{c}{2} & \multicolumn{1}{c}{4} & \multicolumn{1}{c}{6} & 8 & \multicolumn{1}{c}{10} \\
\hline$T_{\mathrm{g}} /{ }^{\circ} \mathrm{C}$ & & 98.5 & 105.1 & 106.0 & 106.3 & 105.4 & 106.2 & 106.3 \\
$T_{\mathrm{m}} /{ }^{\circ} \mathrm{C}$ & 138.7 & & 133.7 & 134.0 & 134.7 & 132.6 & 133.8 & 134.0 \\
$X_{\mathrm{c}} / \%$ & 80.3 & & 64.1 & 57.5 & 62.2 & 57.1 & 56.6 & 51.0 \\
\hline
\end{tabular}

where $\Delta H_{\mathrm{m}}$ is the measured heat of fusion, $\Delta H_{\mathrm{m}}^{\mathrm{o}}$ is the heat of fusion for $100 \%$ crystalline PE, $\phi$ is the SEBS content in the blend, and $w$ is the weight fraction of HDPE with respect to the total weight of PS and HDPE. The value of $\Delta H_{\mathrm{m}}^{\circ}$ for PE was reported to be $293.57 \mathrm{~J} \mathrm{~g}^{-1}{ }^{32}$ The glass transition temperature of the PS phase and the crystallinity of the HDPE phase were determined and the results are summarized in Table I. From the table we can see that the melting point of the HDPE phase decreases from 138.7 to $133.7^{\circ} \mathrm{C}$ after blending with PS; however, it is almost unaffected by the SEBS content. The glass transition temperature of the PS phase increases from 98.5 to $105^{\circ} \mathrm{C}$ after blending with HDPE. A possible reason is the overlapping of the glass transition zone of PS and the melting peak of HDPE, resulting in a false appearance that the $T_{\mathrm{g}}$ of PS increases after blending with HDPE. The crystallinity of the HDPE phase in the blend is much lower than its pure state because the crystallization of the HDPE phase in the blends has to proceed in a confined environment - the nucleation and growth process of HDPE is hindered by the PS phase. Generally, the crystallinity of the HDPE phase in the blend decreases with increasing SEBS content until the content of SEBS exceeds $6 \mathrm{wt} \%$. The crystallinity of the HDPE phase in the blend containing $4 \mathrm{wt} \%$ SEBS is higher than that of the blend containing $2 \mathrm{wt} \%$, possibly due to the morphological change of the blend. In the blend containing $2 \mathrm{wt} \%$ SEBS, HDPE is dispersed in the PS matrix as spherical particles with an average diameter of about $0.3 \mu \mathrm{m}$; hence the crystallization of HDPE is confined to small regions and the growth of the crystallites is limited. On the contrary, in the blend containing $4 \mathrm{wt} \%$ SEBS, the HDPE phase becomes continuous and its domain size greatly increases, so that the crystallization can proceed with less restriction, resulting in higher crystallinity.

\section{CONCLUSIONS}

From the above discussion, the following conclusions can be drawn for the blends of PS with HDPE compatibilized by SEBS:

1. The PS/HDPE blend without SEBS exhibits very poor mechanical properties owing to weak interfacial adhesion. However, PS/HDPE blends with improved mechanical properties can be achieved by addition of SEBS as a compatibilizer because its addition to the blend can enhance the adhesion between the PS and HDPE phases.

2. SEM observation reveals that the unmodified PS/HDPE (80/20) blend exhibits a two-phase structure 
- the spherical HDPE particles are dispersed in the PS matrix and the size distribution of the dispersed particles is very wide. However, after the addition of only $2 \mathrm{wt} \%$ of SEBS, the size of the dispersed particles decreases significantly and their distribution becomes very homogeneous. A bi-continuous two-phase structure appears after the SEBS content exceeds $4 \mathrm{wt} \%$.

3. SEM micrographs of fractured tensile bars show that the unmodified blend fractures in a brittle mode, producing very smooth fracture surfaces. After the addition of SEBS to the blend, transition from brittle to ductile failure takes place. The compatibilized blends exhibit rough fracture surfaces, indicating that plastic deformation has occurred in the tensile process.

4. In the shear rates studied, the viscosity of the blends at $200^{\circ} \mathrm{C}$ hardly changes after addition of $2 \mathrm{wt} \%$ of SEBS. The viscosity increases sharply when the SEBS content increases from 2 to $4 \mathrm{wt} \%$. Further increases in the SEBS content do not have much effect on the viscosity. It is possible that the interfacial conditions and the morphology of the blends are responsible for the rheological behavior of the blends.

5. In the heating curves of the blends, the glass transition of the PS phase partially overlaps with the crystallization peak of the HDPE phase, resulting in a false appearance that the $T_{\mathrm{g}}$ of PS increases after blending with HDPE. The glass transition temperature of the PS phase and the melting point of HDPE are hardly affected by SEBS content. The crystallinity of the HDPE phase in the blend generally decreases with increasing SEBS content.

Acknowledgments. This work was supported by Hong Kong Government Research Grant Council under the grant number HKUST 582/95P. The authors would like to thank the Materials Characterization and Preparation Facility for their help in SEM and DSC study.

\section{REFERENCES}

1. R. Fayt, R. Jerome, and Ph. Teyssie, J. Polym. Sci., Polym. Lett. Ed., 19, 79 (1981)

2. S. Krause, in "Polymer Blends," Vol. 1, D. R. Paul and S. Newman, Ed., Academic Press, New York, N.Y., 1978.

3. L. A. Utracki, "Polymer Alloys and Blends," Carl Hanser Verlag,
New York, N.Y., 1989

4. Z. Horak, V. Fort, D. Hlavata, F. Lednicky, and F. Vecerka, Polymer, 65, 1 (1996).

5. A. Ajji and L. A. Utracki, Polym. Eng. Sci., 36, 1574 (1996).

6. S. Xu, M. Jiang, and J. Shen, Chem. J., Chinese Univ., 16, 315 (1995).

7. S. Xu, M. Jiang, and J. Shen, Polym. J., 27, 607 (1995).

8. S. Xu, M. Jiang, and J. Shen, Polym. J., 28, 226 (1996).

9. D. Henkens, N. Hoen, W. Barentsen, P. Piet, and H. Ladan, J. Polym. Sci. Symp., 62, 309 (1975).

10. M. A. Ramos and E. P. Collar, J. Polym. Eng., 7, 137 (1987).

11. J. W. The and A. Rudin, Polym. Eng. Sci., 31, 1033 (1991).

12. Z. Wang, C. M. Chan, S. H. Zhu, and J. R. Shen, Polymer, in press.

13. W. Barentsen and D. Heikens, Polymer, 14, 579 (1973).

14. T. Li, V. A. Topolkaraev, A. Hiltner, E. Baer, X. Z. Ji, and R. P. Quirk, J. Polym. Sci., Part B: Polym. Phys., 33, 667 (1995).

15. W. M. Barentsen, D. Heikens, and P. Piet, Polymer, 15, 119 (1973).

16. C. E. Lock and D. R. Paul, J. Appl. Polym. Sci., 17, 2791 (1973).

17. S. Matri, J. Nwrvo, and G. Riess, Prog. Colloid Sci., 58, 114 (1975).

18. C. R. Lindsey, D. R. Paul, and J. W. Barlow, J. Appl. Polym. Sci., 16, 1 (1981).

19. R. Fayt, R. Jerome, and Ph. Teyssie, J. Polym. Sci., Polym. Lett. Ed., 26, 25 (1986).

20. R. Fayt, R. Jerome, and Ph. Teyssie, J. Polym. Sci., Part B: Polym. Phys., 27, 775 (1989).

21. R. Fayt and Ph. Teyssie, Polym. Eng. Sci., 30, 937 (1986).

22. R. Fayt, R. Jerome, and Ph. Teyssie, Makromol. Chem., 187, 837 (1986).

23. M. C. Schwarz, J. W. Barlow, and D. R. Paul, J. Appl. Polym. Sci., 35, 2053 (1988).

24. M. C. Schwarz, H. Keskkula, J. W. Barlow, and D. R. Paul, J. Appl. Polym. Sci., 35, 653 (1988).

25. T. Appleby, F. Cser, G. Moad, E. Rizzardo, and C. Stavropoulos, Polym. Bull., 32, 479 (1994).

26. S. A. Xu and M. Jiang, "The Structure, Properties and Toughening Mechanisms of the Plastic-Toughened Plastic System (PS/LDPE/SEBS)," Ph.D. Dissertation, Fudan University, Shanghai, China, 1994.

27. R. Fayt, R. Jerome, and Ph. Teyssie, J. Polym. Sci., Polym. Phys. Ed., 19, 1269 (1981).

28. C. B. Bucknall, "Toughened Plastics," Materials Science Series, Applied Science, London, 1977.

29. R. Fayt, R. Jerome, and Ph. Teyssie, J. Polym. Sci., Polym. Phys. Ed., 20, 2209 (1982)

30. A. Ghaffar and G. Scott, Eur. Polym. J., 14, 631 (1978).

31. I. M. Ward, "Mechanical Properties of Solid Polymers," Wiley, New York, N.Y., 1979, p 277.

32. B. Wunderlich, in "Thermal Analysis," Academic Press, New York, N.Y., 1990, p 418. 